$\xi=$ 줄

\title{
Awareness \& attitude regarding biomedical waste disposal among post-graduate students, under-graduate students \& auxiliary staff of a dental college - a questionnaire survey
}

\author{
Rahul Chopra $^{1}$, Shivani Mathur ${ }^{2}$, Vidya Dodwad ${ }^{3}$, Nikhil Sharma ${ }^{4}$, Siddharth Tevatia ${ }^{5 *}$ \\ ${ }^{1}$ Associate Professor, Department of Periodontology \& Oral Implantology, ITS-CDSR Ghaziabad \\ ${ }^{2}$ Associate Professor, Department of Pedodontics, ITS-CDSR Ghaziabad \\ ${ }^{3}$ Professor\& Head, Department of Periodontology \& Oral Implantology, ITS-CDSR Ghaziabad \\ ${ }^{4}$ Professor, Department of Periodontology \& Oral Implantology, ITS-CDSR, Ghaziabad \\ ${ }^{5}$ Post Graduate Student, Department of Periodontology \& Oral Implantology, ITS-CDSR, Ghaziabad \\ *Corresponding author E-mail:dr.siddharthtevatia@gmail.com
}

\begin{abstract}
Purpose: Indiscriminate disposal of bio medical waste poses a serious threat to environment and human health and is currently a burning issue with increasing health care facilities and associated waste generation. Hence this study assesses the awareness levels and attitude regarding biomedical waste disposal among post-graduates, under-graduates \& auxiliary staff of a dental college.

Materials and Method: This was a cross-sectional study conducted among post-graduates, under-graduates \& auxiliary staff using a questionnaire. A total of 120 participants, 40 in each group answered the questionnaire. The answers were analyzed and graded for each group.

Results: The results depict satisfactory awareness about biomedical waste disposal among post-graduates and under-graduates. However, the auxiliary staff lacks the awareness about proper biomedical waste disposal.

Conclusion: The study reveals that there is a need to increase knowledge among the auxiliary staff regarding biomedical waste management by continuing training program.
\end{abstract}

Keywords: Bio-Medical Waste; Auxiliary Staff; Dental College; Color Coding

\section{Introduction}

As stated by K. Park "Let the waste of the sick not contaminate the lives of healthy".

Health care system in India has advanced terrifically, but this comes with production of a huge amount of Biomedical Waste, which poses a great threat to living beings and environment of a whole (Narang et al., 2012). Biomedical Waste according to (Management and Handling) Rules, 1998 of India can be defined as "Any waste, which is generated during the diagnosis, treatment or immunization of human beings or animals or in research activities pertaining thereto or in the production or testing of biological (Mathur et al., 2012).

Improper and inappropriate disposal has become a major health issue in the recent past. The medical waste generated in India is around 3 million tons per annum out of which about 10 to $35 \%$ of medical waste generated is potentially hazardous, but owing to indiscriminate mixing of this with non-hazardous waste converts entirety waste hazardous (Begum A et al., 2015; Chaudhari K et al. 2015; Kaur D et al., 2015).

The hazardous waste thus generated can cause various diseases related to skin, GIT, respiratory disorders and major ones like HIV or hepatitis. Also if this waste is disposed of before suitable treat- ment it can affect environment rendering air, land and water bodies' contaminated (Selvaraj k et al., 2013).

Dental waste generated includes latex, cotton, plastic, glass, restorative materials, including amalgam, etc which is infected with blood, saliva, etc. of patient. Tracking of waste in US found dental waste to be $3 \%$ of total biomedical waste generated (Khandelwal $\mathrm{V}$ et al., 2013). Even though amount of dental waste seems to be small, but it can be as hazardous as medical waste leading to various health problems among the health care providers, patients' etc. (Nayak A et al., 2015).

With increasing global awareness about biomedical Waste Management and associated hazards, this present study was conducted to assess the awareness \& attitude regarding biomedical waste disposal among post-graduates, under-graduates \& auxiliary staff in a private dental college in UP, India.

\section{Materials and methods}

The study was a questionnaire based study conducted at ITS Dental College, Muradnagar, Ghaziabad. The questionnaire consisted of 15 closed-ended questions (Figure 1), which were given to a total of 120 participants (40 Post-Graduate students, 40 UnderGraduate students \& 40 Auxiliary Staff members). The questions 
evaluated the basic knowledge and attitude towards the biomedical waste disposal of the participants. The auxiliary staffs requiring help was explained questions about the language of their understanding. All the questionnaires from each group were corrected. For ease of understanding overall correct answers obtained were categorized into Good (>12 correct answers), Fair (7-12 correct answers) and Poor ( $<7$ correct answers). The data was compiled in Excel worksheet and percentage was used to interpret the results.

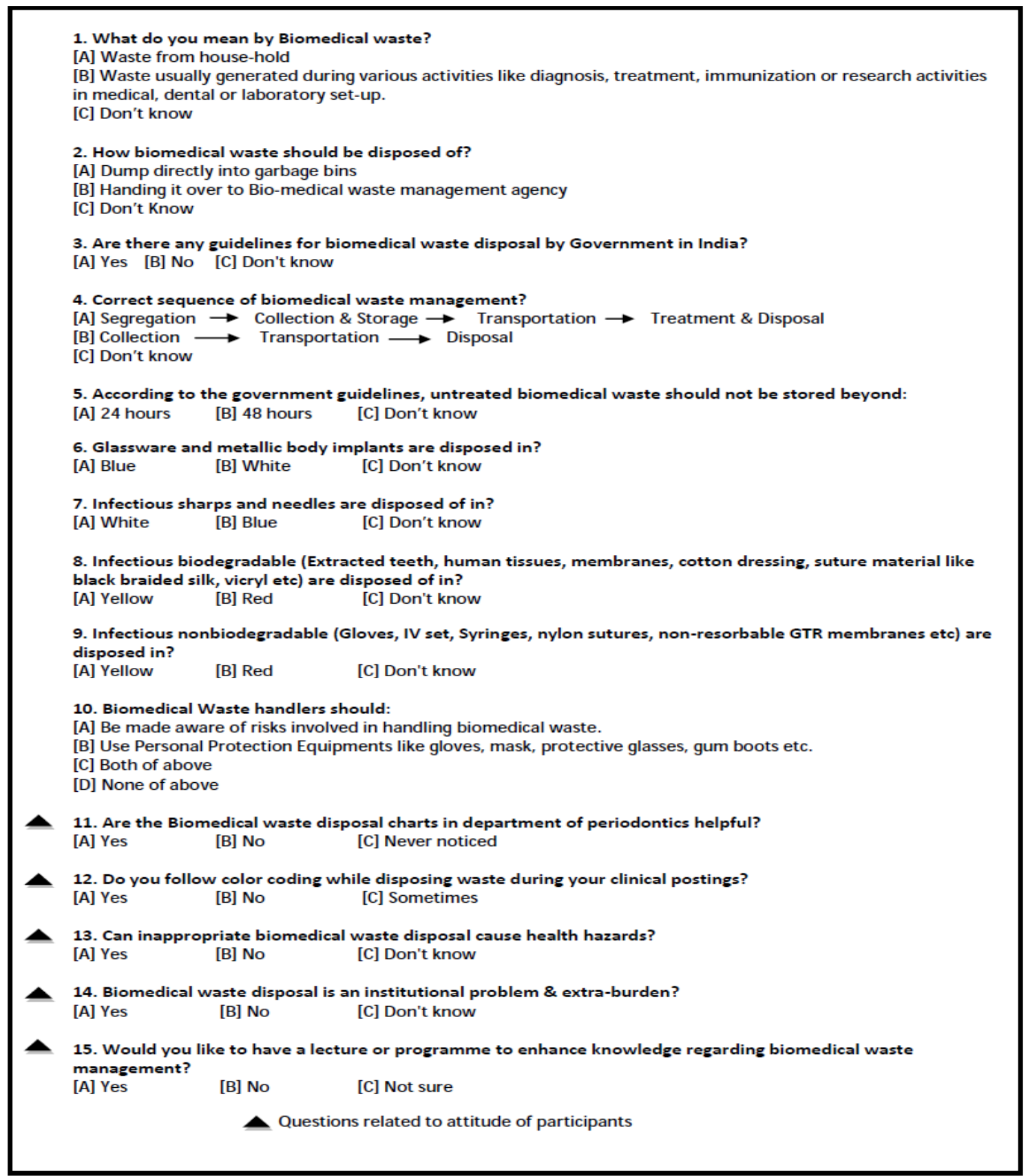

Fig. 1: Questionnaire to Access the Awareness \& Attitude of the Participants.

\section{Results}

All the 120 participants completed the questionnaire and submitted the forms. On evaluation the results revealed, $82 \%$ of Postgraduates had good knowledge and attitude for Bio-medical waste
(BMW) disposal, and $18 \%$ had been fair while none fell into poor category. Among the under-graduates $43 \%$ good, $39 \%$ fair and $18 \%$ had poor knowledge and attitude for BMW disposal. For the auxiliary group (Aux) 23\% good, 37\% fair, $40 \%$ had poor knowledge and attitude regarding BMW disposal (Figure 2). 


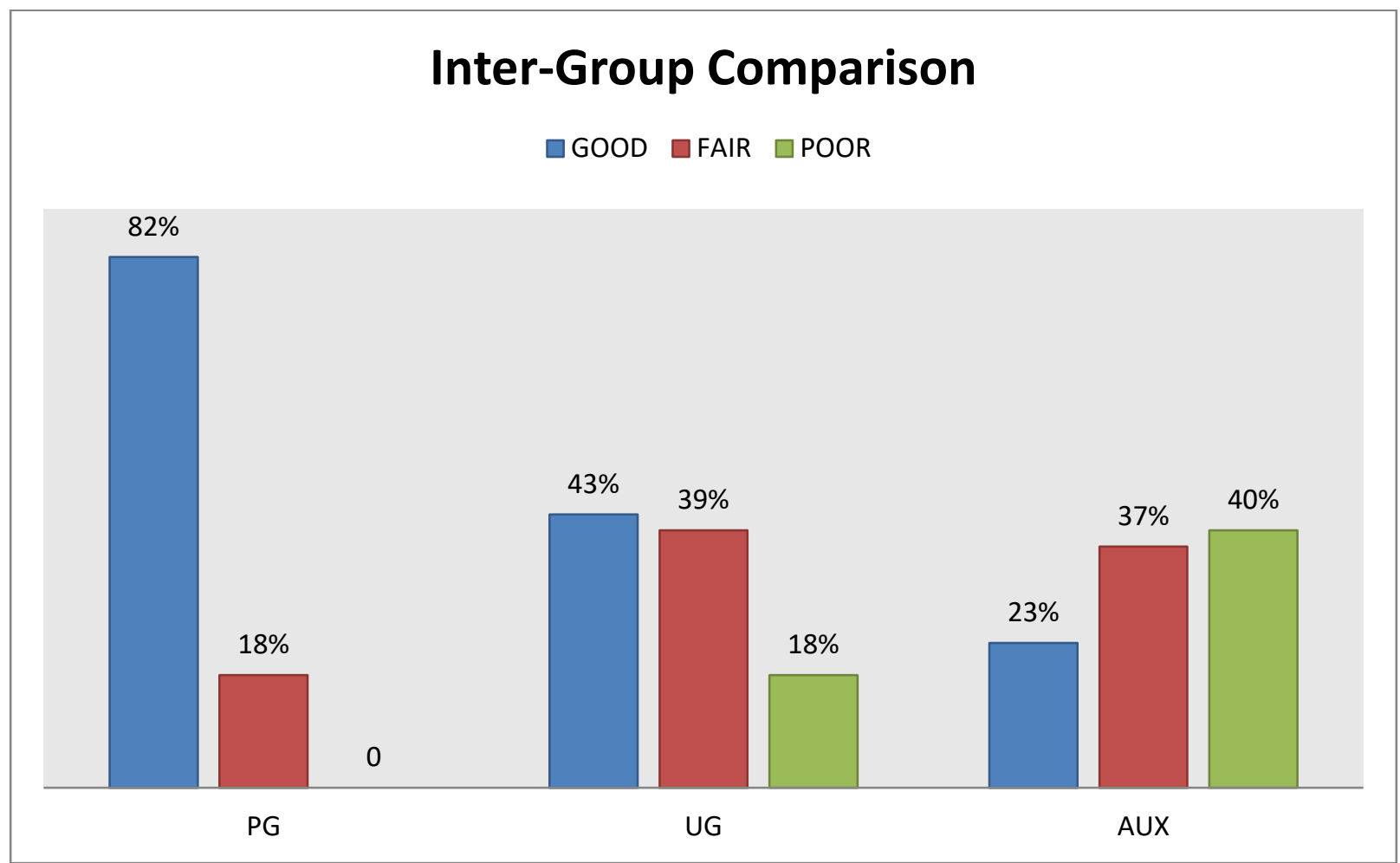

Fig. 2: Comparison of Three Groups Regarding Awareness \& Attitude towards BMW Disposal.

Table 1 depicts results of understanding of color coding for BMW disposal, and Table 2 demonstrate results to questions regarding the attitude of participants towards BMW disposal.

Table 1: Understanding of Color Coding Amongst the Three Groups

\begin{tabular}{|c|c|c|c|c|}
\hline & & Post-Graduates & Under-Graduates & Auxiliary Staff \\
\hline \multirow[t]{3}{*}{ Understanding of color coding } & Black & $40(100 \%)$ & $32(80 \%)$ & $29(73 \%)$ \\
\hline & Blue & $34(85 \%)$ & $22(55 \%)$ & $16(40 \%)$ \\
\hline & Yellow & $36(90 \%)$ & $24(60 \%)$ & $21(53 \%)$ \\
\hline
\end{tabular}

Table 2: Assessment of Attitude of Participants Regarding BMW Disposal

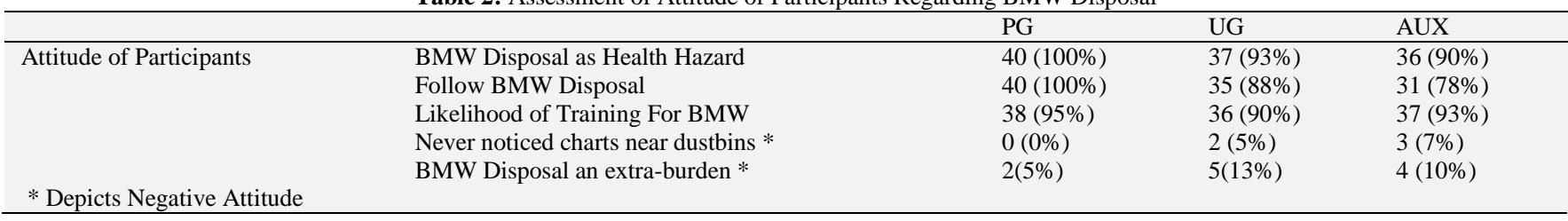

\section{Discussion}

This questionnaire survey was conducted to access the awareness and attitude of post-graduates (PG), under-graduates (UG) \& auxiliary staff of private dental college regarding biomedical waste disposal. To simplify the scoring was categorized into Good $(>12$ correct answers), Fair (7-12 correct answers) and Poor ( $<7$ correct answers). As expected the overall awareness of PG's was better than UGs, which was in turn better than auxiliary staff. About $82 \%$ of PG's had good and $18 \%$ had fair awareness regarding BMW. Furthermore, UGs impressed with $43 \%$ falling into good, $39 \%$ in fair and $18 \%$ in poor category. Amongst auxiliary staff $23 \%$ had good, $37 \%$ fair and $40 \%$ poor awareness.

The results of present study show impressive results for PG group with not even a single candidate falling in poor category with regard to overall assessment of BMW, which was similar to a previously reported study (Chaudhari et al., 2015) However, most of the studies have not segregated results of dentist group into PG and UG group. On evaluating UG group, we can see satisfactory knowledge similar to studies done (Narang et al., 2012; Chaudhari et al., 2015; Sharma et al., 2013; Saini et al., 2013). For auxiliary group, the results were unsatisfactory, which were similar to previous studies (Narang et al., 2012; Sharma et al., 2013).

However, when evaluating awareness for color coding for all the groups it was seen that results were better compared to other studies (Narang et al., 2012; Sharma A et al., 2013; Malini A et al., 2015) for auxiliary group and comparable to other studies (Saini $R$ et al., 2013; Chaudhari K et al., 2015) for PG and UG group. This can be attributed to usefulness for color coding charts near the dustbins. Regarding the attitude for safe BMW management, it was found that all the groups had a positive approach. The results were comparable to studies by Chaudhari et al., 2015; Malini et al., 2015) and better compared to study (Radha R et al., 2012).

Safe management of BMW is duty and responsibility of every single healthcare provider. Most of the above-mentioned studies noted satisfactory awareness among the dentist. However, auxiliary staff remained matter of concern. Studies have advocated use of color coding charts in institutes (Sharma et al., 2013), training program (Mohan et al., 2012), attitude of staff etc as paramount importance for maintaining standards of BMW management. In our study, we found successful implementation of color coding charts was useful for all the groups. Also, most of the participants had positive attitude towards BMW management. So, continuous 
training of participants should be considered so as to achieve high goals set for management of BMW.

\section{Conclusion}

Within the limits of present study it can be concluded:

- PG group had better awareness regarding BMW management than UG group which in turn fared better than Auxiliary group.

- All groups had a positive attitude towards BMW management.

- Usefulness of color coding charts can be considered as highlight of the study.

Further continuous training should be integral part of BMW management, and its usefulness should be evaluated.

\section{References}

[1] Begum A, Janaki V, Subrahmanyam GVS, Devraj K. Knowledge about biomedical waste management among health care professionals in a tertiary care teaching hospital, Telangana. IOSR-JDMS 2015; 14 (12):31-38

[2] Chaudhari K, Patel J, Rudani J, Dawda D. Knowledge, Attitude and Practices among Dentists regarding Bio-Medical Waste Management in Ahmedabad City, Gujarat: A Questionnaire Based Study. Int J Oral Health Med Res 2015; 2 (1):23-26.

[3] Kaur D, Pandey A, Tekwani D, Bedekar M, Pai M, Agarwal M Awareness of Bio-medical waste management among the health care workers in rural area. IJBAMR 2015; 4 (4):351-357.

[4] Khandelwal V, Khandelwal S, Thakur JS. Health care waste disposal among private dentist in an Indian city: it's time to act. Int $\mathbf{J}$ Infect Control 2013; 9: 1-5. https://doi.org/10.3396/ijic.v9i2.016.13

[5] Malini A, Eshwar B. Knowledge, Attitude and Practice of Biomedical waste management among health care personnel in a tertiary care hospital in puducherry. IJBR 2015; 6 (3):172-176.

[6] Mathur P, Patan S, Shobhawat SA. Need of biomedical waste management system in hospitals - an emerging issue - a review. Curr. World Environ.2012; 7(1): 117-124.

[7] Mohan R, Prasad MV, Kumar KS. Impact of Training on Bio Medical Waste Management - A Study and Analysis. IJMMS 2012; 2 (6):69-80.

[8] Narang SR, Manchanda A, Singh S, Verma N, Padda S. Awareness of biomedical waste management among dental professionals and auxiliary staff in Amritsar, India. OHDM 2012; 11 (4):162-169.

[9] Nayak A, Chopra R, Kaur R. Biomedical Waste Management: A Review. J Adv Med Dent Scie Res 2015; 3 (1):130-133.

[10] Radha R. Assessment of existing Knowledge, Attitude and Practices regarding Biomedical waste management among the health care workers in a tertiary care rural hospital. IJHSR 2012; 2(7):14-19.

[11] Saini R, Pithon MM, Singh HK, Popoff DV. Knowledge of Biomedical Waste Management among the students of Rural dental College, Maharastra, India. Int J Experiment Dent Sci 2013; 2 (1): 24-26. https://doi.org/10.5005/jp-journals-10029-1034.

[12] Selvaraj k, Sivaprakasam P, Nelson BTSB, Kumar GHM, Norman $\mathrm{P}$, Pandiyan KR. Knowledge and practice of Biomedical Waste Management among the medical practitioners of Kanchipuram town, India. Int.J.Microbiol.App.Sci 2013; 2 (10): 262-267.

[13] Sharma A, Sharma V, Sharma S, Singh P. Awareness of Biomedical Waste Management Among Health Care Personnel in Jaipur, India. OHDM 2013; 12 (1): 32-40. 